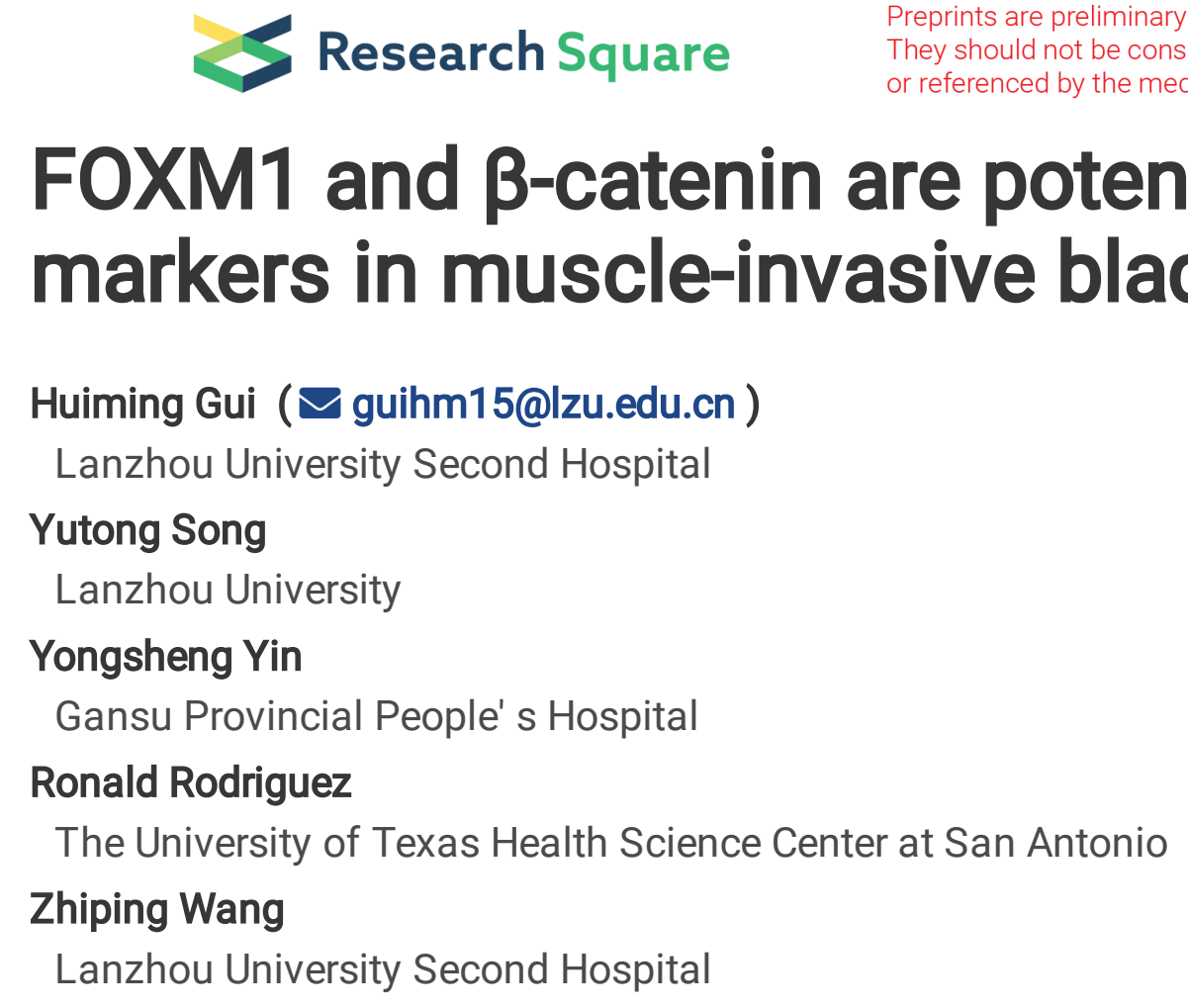

\author{
Huiming Gui ( $\nabla$ guihm15@lzu.edu.cn ) \\ Lanzhou University Second Hospital \\ Yutong Song \\ Lanzhou University \\ Yongsheng Yin \\ Gansu Provincial People's Hospital

\section{Ronald Rodriguez} \\ The University of Texas Health Science Center at San Antonio

\section{Zhiping Wang} \\ Lanzhou University Second Hospital
}

\title{
FOXM1 and $\beta$-catenin are potential prognostic markers in muscle-invasive bladder carcinoma
}

\section{Research}

Keywords: muscle-invasive bladder carcinoma, prognosis marker, FOXM1, $\beta$-catenin

Posted Date: December 15th, 2020

DOI: https://doi.org/10.21203/rs.3.rs-126609/v1

License: (c) (i) This work is licensed under a Creative Commons Attribution 4.0 International License. Read Full License 


\section{Abstract}

\section{Background}

Forkhead box protein M1 (FOXM1) and $\beta$-catenin were confirmed to associate with numerous cancers, which attracted more attention in recent years. Our research investigated the expression of FOXM1 and $\beta$ catenin and their effects on prognosis of patients with muscle-invasive bladder cancer (MIBC).

\section{Methods}

In this study, FOXM1 and $\beta$-catenin expression was detected by immunohistochemistry in a study cohort including $121 \mathrm{MIBC}$ patients.

\section{Results}

The results showed significant correlations of FOXM1 and $\beta$-catenin expression with tumor stage, tumor grade, and lymph node metastases in MIBC patients. Univariate analysis showed that patients with high FOXM1 $(H R=2.986 ; P=0.011)$ and low $\beta$-catenin $(H R=2.623 ; P=0.001)$ expression levels, advanced tumor stage $(H R=2.325 ; P=0.002)$, advanced tumor grade $(H R=2.790 ; P<0.001)$, tumor size $(H R=$ 2.080; $P=0.020)$, lymph node metastases $(H R=3.392 ; P<0.001)$, or recurrence status $(H R=2.016 ; P=$ 0.011 ) had a significantly higher risk of worse overall survival (OS). In the multivariate analysis, tumor stage $(H R=2.095 ; P=0.009)$, tumor grade $(H R=1.962 ; P=0.019)$, FOXM1 expression $(H R=2.196 ; P=$ $0.017)$ and lymph node metastases $(H R=2.136 ; P=0.015)$ predicted worse OS.

\section{Conclusion}

Therefore, FOXM1 and $\beta$-catenin expression was relevant to MIBC incidence, tumor stage, tumor grade, metastasis, and survival and might be a reliable index to judge the prognosis of patients with MIBC.

\section{Introduction}

Bladder carcinoma is a common cancer of the urinary tract, with a poor prognosis in 2020 worldwide [1]. About three-quarter of patients had non muscle invasive bladder carcinoma (NMIBC), including papillary carcinoma confined to the mucosa ( $\mathrm{pTa}$ ) or lamina propria ( $\mathrm{pT} 1)$, and the rest of patients had muscle invasive bladder carcinoma (MIBC; T2-T4) at the time of diagnosis [2].

According to the characteristics of pathology and clinical prognosis, transurethral resection of bladder (TURB) was performed in NMIBC patients, and then intravesical instillation of Bacille Calmette-Guérin vaccine or mitomycin $\mathrm{C}$ was performed [3]. Although radical cystectomy was effective in patients with MIBC, approximately one-half of patients would have metastasis and recurrence and eventually die of the disease [4]. To date, there were no established biomarkers that could be able to predict progression. Therefore, early diagnosis and effectual therapy of MIBC required molecular prognostic biomarkers. 
Forkhead box protein M1 (FOXM1) was known as a predictive factor for tumor progression, and its expression was relevant to a bad prognosis in numerous cancers, such as prostate carcinoma [5], breast carcinoma [6], hepatic carcinoma [7], renal carcinomas [8], and melanoma [9]. However, the correlation between the FOXM1 expression pattern in different human MIBC tissues and its role in carcinoma development was still unclear. In addition, other studies reported that FOXM1 promoted the nuclear localization of $\beta$-catenin nuclear and controlled the expression of Wnt target gene and tumorigenesis [10].

The purposes of the present work were first to study, by immunohistochemistry (IHC), FOXM1 and $\beta$ catenin expression according to clinical and pathological parameters and second to evaluate whether FOXM1 and $\beta$-catenin could help predict long-term survival outcomes in MIBC patients.

\section{Materials And Methods}

\section{Patients}

121 patients were enrolled totally in our study, who were first diagnosed with MIBC (stage pT2 and pT4) at a single academic center from 2011 to 2016 . The inclusion criteria were as follows: all patients were confirmed by adequate imaging and clinical examination, finally diagnosed as MIBC by pathological examination, and then discharged patients were followed up or examined for one or more times. We excluded patients who had previously been diagnosed with any stage of MIBC, received radiotherapy, chemotherapy or immunotherapy, and suffered from other cancers. A pathologist working in uropathology graded and reassessed histopathological variables of the patients included totally in our study on the basis of the World Health Organization (WHO) classification criteria of 1973 and 2016. Our research was approved by the Second Hospital of Lanzhou University and then followed up retrospectively.

\section{Immunohistochemical staining}

Performing IHC as previous description. Tissues were incubated with anti-FOXM1 and $\beta$-catenin primary antibodies overnight at $4^{\circ} \mathrm{C}$ (diluted at 1:50 and 1:100 respectively). We got the FOXM1 and $\beta$-catenin primary and the secondary antibodies from Cell Signaling Technology (Beverly, MA, USA).

\section{Evaluation of IHC}

The slides were reviewed and scored parallel by two researchers without knowledge of the clinical data from patients, the product of the proportion of positive tumor cells and the staining intensity was used as standards of grading. The proportion of positive tumor cells was divided into 4 categories: $1(<25 \%), 2$ (25-50\%), $3(50-75 \%)$, and 4 (> 75\%). The corresponding scores of staining intensity for no, shallow, medium and corresponding deep staining were $0,1,2,3$. The ultimate immunostaining score for each protein was calculated as these two values, providing an allred total score ranging from 0 to 12 . So the ultimate staining index is 0-3 for low protein expression, while the ultimate staining index is 4-12 for high protein expression. 


\section{Statistical analysis}

Chi-square $(\chi 2)$ tests was used to test the relation between the expression of FOXM1 and $\beta$-catenin and characteristics of clinicopathology. Overall survival (OS) was analyzed by Kaplan Meier method and Log rank test. Univariate and multivariate survival analysis was performed by Cox regression analysis. For whole statistical tests, $P$ value was bilateral, $P<0.05$ was confirmed to be statistically significant. SPSS version 22.0 software was used for statistical analysis (SPSS Inc.).

\section{Results}

The positive expression of FOXM1 and $\beta$-catenin in tissues of MIBC and their relationship with clinic pathology

Table 1 showed the clinicopathological variables of all patients included. We enrolled 121 MIBC patients (median age 55.5 years; range 31-91 years), including 80 men and 41 women in this study. The median follow-up period was 29.5 months (interquartile range 1-96 months).

Potential relationship between FOXM1 or $\beta$-catenin and other clinicopathological factors was explored (Table 1). Our results suggested that elevated expression of FOXM1 or $\beta$-catenin was significantly related to high tumor stage, recurrence status, tumor size, and lymph node metastases (LNM) in MIBC (all $P<0.05)$. In addition, the expression of $\beta$-catenin had relevance to tumor grade $(P<0.01)$. Moreover, there was a significant relation between high FOXM1 and low $\beta$-catenin levels $(P<0.001)$ by using Spearman rank correlation coefficient analysis.

\section{FOXM1 and $\beta$-catenin expression in MIBC and normal bladder tissues}

The expression of FOXM1 protein was assessed in the nuclei of primary bladder cancer cells, and the expression of $\beta$-catenin protein in tumor cells had different degrees of cytoplasmic and membrane staining characteristics, as shown in Figure $1 \mathrm{~A}$ and $\mathrm{B}$. IHC was performed to test FOXM1 and $\beta$-catenin expression in 60 patients with MIBC (Table 2), and we found high FOXM1 protein expression in 44 (73.3\%) patient tissues and in $24(40.0 \%)$ normal bladder tissues. The difference between these two groups had statistical significance $(P=0.031)$. Among 60 MIBC patient tissues, $45(75.0 \%)$ had high $\beta$ catenin protein-expression, which was significantly higher than that in the adjacent normal control tissues $(25,41.7 \%)(P<0.047)$.

\section{Correlation between FOXM1 and $\beta$-catenin expression with OS in MIBC}

We found that upregulate of FOXM1 and $\beta$-catenin expression (Fig $1 \mathrm{C}$ and D) were relevant to poor OS in MIBC patients by the Kaplan-Meier analyses $(P<0.05)$. The median survival for 121 patients from our research was 66 months. The low-FOXM1 group exhibited significantly longer OS (median OS $=74.5$ months; mean OS = 72.74 \pm 16.19 months) than the high-FOXM1 group (median OS = 64 months; mean $\mathrm{OS}=60.71 \pm 21.69$ months $)(\mathrm{P}<0.001)$. The high $\beta$-catenin group exhibited significantly shorter OS (median OS $=59$ months; mean $=59.54 \pm 20.31$ months) than the low $\beta$-catenin group (median OS $=$ 
75.50; mean $=72.41 \pm 18.73$ months $)(P<0.001)$. Cox proportional hazard regression model was used to evaluate the effect of FOXM1 and $\beta$-catenin expression on OS, as shown in Table 3, and we performed a univariate analysis to estimate the mortality risk in MIBC patients. High expression of FOXM1 (HR = 2.986, $P=0.011)$, low expression of $\beta$-catenin $(H R=2.623, P=0.001)$, advanced tumor stage $(H R=2.325$, $P=0.002)$, tumor grade $(H R=2.790 ; P<0.001)$, tumor size $(H R=2.080 ; P=0.020), L N M(H R=3.392 ; P<$ $0.001)$, or recurrence status $(H R=2.016 ; P=0.011)$ were related to a significantly higher risk of death. In the multivariate analysis, the expression of FOXM1 $(H R=2.196, P=0.017)$, tumor stage $(H R=2.095 ; P=$ $0.009)$, tumor grade $(H R=1.962 ; P=0.019)$, and $L N M(H R=2.136, P=0.015)$ had significant relevance to OS.

\section{Discussion}

FOXM1 activated genes that regulated tumor cell cycle progression, and the over-expression of FOXM1 was relevant to unfavourable survival outcomes of numerous tumors [11]. Yang et al. [12] reported that in bladder carcinoma cells, downregulation of FOXM1 suppress cell migration and invasion. Roh et al. [13] reported that FOXM1 can be used as a useful tumor marker that are associated with anticancer drug resistance properties in NMIBC patients. Chen et al. [14] confirmed upregulation of FOXM1 was related to bad progression free survival of NMIBC patients. However, the role and clinical value of FOXM1 expression in MIBC were still not investigated in depth.

Our study results showed the following: first, high expression of FOXM1 predicted a shorter survival time in patients with MIBC; second, upregulation of FOXM1 was relevant to higher tumor stage, tumor grade and lymph node metastases for MIBC patients but was not related to age, tumor size, histologic type or recurrence status; third, compared with normal tissues, the expression of FOXM1 was increased in MIBC tissues, and was positively relevant to the expression of $\beta$-catenin. The effect of FOXM1 on the OS of MIBC patients was investigated in this retrospective cohort study. To explore the transformation efficiency of them, the clinicopathological characteristics of FOXM1 and $\beta$-catenin were compared in multivariate analysis. FOXM1 promoted the nuclear localization of $\beta$-catenin and cancer cell tumorigenesis [10]. High FOXM1 transcription was relevant to higher tumor stage and tumor grade. However, FOXM1 was demonstrated to be an independent OS predictor in our study, which was better than $\beta$-catenin in MIBC.

FOXM1 protein expression in bladder carcinoma tissues was detected by $\mathrm{IHC}$ and was highly expressed in $73.3 \%$ of 60 patients with MIBC, which was significantly higher than that in normal bladder tissues (40.0\%). This result indicated that FOXM1 protein abnormal expression was involved in the occurrence of MIBC, an observation that was entirely consistent with the findings of Zhao et al [15] in muscleinvasive bladder cancer. We found that high FOXM1 protein expression was related to the tumor stage, degree of differentiation, LNM, and survival outcome of MIBC patients. This result agreed with the study by Gong et al [16], and the present study also demonstrated that the upstream and downstream regulatory factors of FOXM1 (such as FOXO3, AKT and PI3k) might be valuable drug targets, which was worthy of further study for bladder cancer. Given these findings, FOXM1 could be considered an oncogene, and its activation may contribute to MIBC progression and a poor prognosis. The biological 
mechanism of FOXM1 explained its prognostic significance in NMIBC. FOXM1 was known as an important transcriptional factor, which provided a balanced transcription program to guarantee suitable growth and maturation during embryonic development, and provided the basis for better diagnosis and treatment of tumor, congenital diseases and other developmental diseases [17]. FOXM1 was suspected to play a role in determining phenotype and promoting invasiveness in the development of molecular subtypes of BC [18].

The Wnt/ $\beta$-catenin pathway has been related to the development and progression of $B C[18,19]$. In this research, we found that the high expression of $\beta$-catenin protein was apparently higher in MIBC tissues than in pair-matched adjacent normal bladder tissues. Moreover, the high expression of $\beta$-catenin was relevant to tumor stage, tumor grade, LNM, and a poor prognosis in MIBC. Our findings agreed with those of Elsherif et al [20], who reported that $\beta$-catenin expression was positively correlated with tumor stage, $\mathrm{LNM}$, and poor OS. These results indicated that abnormal $\beta$-catenin expression was involved in the occurrence and metastasis of NMIBC, in agreement with the report of Senol et al [21]. This study also demonstrated a significant inverse relationship between the expression of FOXM1 and $\beta$-catenin from $\mathrm{MIBC}$, raising the possibility that $\beta$-catenin plays a role in MIBC progression and prognosis.

Our study had several limitations, including the small sample size and the proportion of patients who were lost to follow up due to many socioeconomic factors. Second, we performed correlation analyses using prognostic information, but owing to these data were not available, we could not consider indicators such as recurrence free survival rate and progression free survival rate. Third, this study was a retrospective single center research. Therefore, more comprehensive researches are needed including larger patient population to assess IHC markers.

In conclusion, this was the first study to analyze the prognostic significance of two important cancer biomarkers in a large cohort of MIBC patients. We showed that FOXM1 is a better predictor of OS in MIBC patients than $\beta$-catenin. The findings in our study highlighted the potential effect of FOXM1 and $\beta$-catenin on prognosis for MIBC, and suggested that they may be useful molecular markers of progression in MIBC. According to these results in our research and others, FOXM1 and $\beta$-catenin may be predictive factors in MIBC and serve as novel targets for clinical treatment. Identification of new molecular markers may also be the first step in precisely defining the high-risk molecular profiling of MIBC.

\section{Abbreviations}

Cl: Confidence interval; MIBC: Muscle-invasive bladder carcinoma; LNM: Lymph node metastasis; HR: Hazard ratio; OS: Overall survival.

\section{Declarations}

\section{Acknowledgments}

Not applicable 


\section{Funding}

This work was supported by grants from GSWSKY2016-18 Scientific Research Project of Health Industry of Gansu Province (No: GSWSKY2016-18)

\section{Availability of data and materials}

All data generated or analysed during this study are included in this published article

\section{Authors' contributions}

Conceived and designed the experiments: ZPW. Performed the experiments: HMG. Analysed the data: HMG, YTS, YSY, RR, ZPW. Contributed reagents/materials/ analysis tools: HMG, YTS. Wrote the paper: HMGL, ZPW. All authors have read and approved the final manuscript.

\section{Ethics approval and consent to participate}

The samples were used in accordance with the principles of the Declaration of Helsinki and the guidelines of the Second Hospital of Lanzhou University Ethical Review Board for Medical Research Involving Human Subjects (approval number: 2016A-070). Written informed consent was obtained from all patients

\section{Consent for publication}

Not applicable.

\section{Disclosure of conflict of interest}

None.

\section{Publisher's Note}

Springer Nature remains neutral with regard to jurisdictional claims in published maps and institutional affiliations

\section{Author details}

1冈lnstitute of Urology, Lanzhou University Second Hospital, Key Laboratory of Gansu Province for Urological Diseases, Clinical Center of Gansu Province for Nephro-urology, Lanzhou University, Lanzhou, China. 2. Department of Urology, Gansu Provincial People's Hospital, Lanzhou, China. 3. Department of Urology, University of Texas Health Science Center at San Antonio, 7703 Floyd Curl Drive, San Antonio, TX 78229-3900, USA

\section{References}


1. Patel VG, Oh WK, Galsky MD. Treatment of muscle-invasive and advanced bladder cancer in 2020. CA Cancer J Clin. 2020; 0:1-20.

2. Witjes JA, Bruins HM, Cathomas R, Comperat EM, Cowan NC, Gakis G, Hernandez V, Linares Espinos E, Lorch A, Neuzillet Y, et al. European Association of Urology Guidelines on Muscle-invasive and Metastatic Bladder Cancer: Summary of the 2020 Guidelines. Eur Urol. 2020; S0302-2838(20)30230$\mathrm{X}$.

3. Taylor J, Becher E, Steinberg GD. Update on the guideline of guidelines: non-muscle-invasive bladder cancer. BJU Int. 2020;125(2):197-205.

4. Grossman HB, Natale RB, Tangen CM, Speights VO, Vogelzang NJ, Trump DL, deVere White RW, Sarosdy MF, Wood DP, Jr., Raghavan D, et al. Neoadjuvant chemotherapy plus cystectomy compared with cystectomy alone for locally advanced bladder cancer. N Engl J Med. 2003;349(9):859-66.

5. Kim MY, Jung AR, Kim GE, Yang J, Ha US, Hong SH, Choi YJ, Moon MH, Kim SW, Lee JY, et al. High FOXM1 expression is a prognostic marker for poor clinical outcomes in prostate cancer. $\mathrm{J}$ Cancer. 2019;10(3):749-56.

6. Arceci A, Bonacci T, Wang X, Stewart K, Damrauer JS, Hoadley KA, Emanuele MJ. FOXM1 Deubiquitination by USP21 Regulates Cell Cycle Progression and Paclitaxel Sensitivity in Basal-like Breast Cancer. Cell Rep. 2019;26(11):3076-86 e6.

7. Liang C, Zhao J, Ge H, Li G, Wu J. Clinicopathological and prognostic significance of FoxM1 in hepatocellular carcinoma patients: a meta-analysis. Onco Targets Ther. 2018;113561-71.

8. Liu F, Li N, Liu Y, Zhang J, Zhang J, Wang Z. Homeodomain interacting protein kinase-2 phosphorylates FOXM1 and promotes FOXM1-mediated tumor growth in renal cell carcinoma. J Cell Biochem. 2019; 20(6):10391-401.

9. Lee VS, McRobb LS, Moutrie V, Santos ED, Siu TL. Effects of FOXM1 inhibition and ionizing radiation on melanoma cells. Oncol Lett. 2018;16(5):6822-30.

10. Zhang N, Wei P, Gong A, Chiu WT, Lee HT, Colman H, Huang H, Xue J, Liu M, Wang Y, et al. FoxM1 promotes beta-catenin nuclear localization and controls Wnt target-gene expression and glioma tumorigenesis. Cancer Cell. 2011;20(4):427-42.

11. Jazeel F. Limzerwala KBJ, Jake A. Kloeber, Brian A. Davies, Cheng Zhang, Ines Sturmlechner, Jian Zhong, Raul Fierro Velasco. FoxM1 insufficiency hyperactivates Ect2-RhoA-mDia1 signaling to drive cancer. Nature Cancer. 2020; 1010-24.

12. Yang $X$, Shi Y, Yan J, Fan H. Downregulation of FoxM1 inhibits cell growth and migration and invasion in bladder cancer cells. Am J Transl Res. 2018;10(2):629-38.

13. Roh YG, Mun JY, Kim SK, Park W, Jeong MS, Kim TN, Kim WT, Choi YH, Chu IS, Leem SH. Fanconi Anemia Pathway Activation by FOXM1 Is Critical to Bladder Cancer Recurrence and Anticancer Drug Resistance. Cancers (Basel). 2020;12(6).

14. Rinaldetti S, Wirtz R, Worst TS, Hartmann A, Breyer J, Dyrskjot L, Erben P. FOXM1 predicts disease progression in non-muscle invasive bladder cancer. J Cancer Res Clin Oncol. 2018;144(9):1701-9. 
15. Rinaldetti S, Wirtz RM, Worst TS, Eckstein M, Weiss CA, Breyer J, Otto W, Bolenz C, Hartmann A, Erben P. FOXM1 predicts overall and disease specific survival in muscle-invasive urothelial carcinoma and presents a differential expression between bladder cancer subtypes. Oncotarget. 2017;8(29):47595606.

16. Yao S, Fan LY, Lam EW. The FOXO3-FOXM1 axis: A key cancer drug target and a modulator of cancer drug resistance. Semin Cancer Biol. 2018;5077-89.

17. Bella L, Zona S, Nestal de Moraes G, Lam EW. FOXM1: A key oncofoetal transcription factor in health and disease. Semin Cancer Biol. 2014;2932-9.

18. Eriksson P, Aine M, Veerla S, Liedberg F, Sjodahl G, Hoglund M. Molecular subtypes of urothelial carcinoma are defined by specific gene regulatory systems. BMC Med Genomics. 2015;825.

19. Chen $Y$, Peng $Y, X u Z$ Z, Ge B, Xiang X, Zhang T, Gao L, Shi H, Wang C, Huang J. Knockdown of IncRNA SNHG7 inhibited cell proliferation and migration in bladder cancer through activating Wnt/betacatenin pathway. Pathol Res Pract. 2019;215(2):302-7.

20. Elsherif E, Elbaky TA, Elserafy F, Elkady N, Dawood M, Gaber MA, Badawy A, Gharabawy ME. betacatenin and SKP2 proteins as predictors of grade and stage of non-muscle invasive urothelial bladder carcinoma. Chin Clin Oncol. 2016;5(1):6.

21. Senol S, Yildirim A, Ceyran B, Uruc F, Zemheri E, Ozkanli S, Akalin I, Ulus I, Caskurlu T, Aydin A. Prognostic significance of survivin, beta-catenin and p53 expression in urothelial carcinoma. Bosn $\mathrm{J}$ Basic Med Sci. 2015;15(4):7-14.

\section{Tables}

Table 1 Clinicopathological features of 121 MIBC patients stratified by FOXM1 and $\beta$-catenin expression 


\begin{tabular}{|c|c|c|c|c|c|c|c|}
\hline \multirow[t]{2}{*}{ Characteristic } & \multirow[t]{2}{*}{ All patients, n (\%) } & \multicolumn{3}{|c|}{ FOXM1 expression } & \multicolumn{3}{|c|}{$\beta$-catenin expression } \\
\hline & & High & Low & $\mathrm{P}$ & High & Low & $\mathrm{P}$ \\
\hline Age (years, n (\%)) & & & & 0.707 & & & 0.854 \\
\hline$<60$ & $52^{\prime}$ & 31 & 21 & & 28 & 24 & \\
\hline$\geq 60$ & 69 & 44 & 25 & & 39 & 30 & \\
\hline Gender, n (\%) & & & & 0.846 & & & 0.565 \\
\hline Female & 41 & 26 & 15 & & 21 & 20 & \\
\hline Male & 80 & 49 & 31 & & 46 & 34 & \\
\hline pT classification & & & & 0.024 & & & 0.018 \\
\hline pT2-3 & 57 & 29 & 28 & & 25 & 32 & \\
\hline pT4 & 64 & 46 & 18 & & 42 & 22 & \\
\hline Tumor grade & & & & 0.295 & & & $<0.001$ \\
\hline $1-2$ & 65 & 37 & 28 & & 25 & 40 & \\
\hline 3 & 56 & 38 & 18 & & 42 & 14 & \\
\hline Recurrence status & & & & 0.005 & & & $<0.001$ \\
\hline Yes & 65 & 48 & 17 & & 49 & 16 & \\
\hline No & 56 & 27 & 29 & & 18 & 38 & \\
\hline Tumor size, n (\%) & & & & 0.005 & & & 0.001 \\
\hline$<3 \mathrm{~cm}$ & 39 & 17 & 22 & & 13 & 26 & \\
\hline$\geq 3 \mathrm{~cm}$ & 82 & 58 & 24 & & 54 & 28 & \\
\hline LNM, n (\%) & & & & 0.002 & & & $<0.001$ \\
\hline No & 58 & 27 & 31 & & 15 & 43 & \\
\hline Yes & 63 & 48 & 15 & & 52 & 11 & \\
\hline Histological subtype, n (\%) & & & & 0.342 & & & 0.062 \\
\hline Non-UBC & 23 & 12 & 11 & & 17 & 6 & \\
\hline UBC & 98 & 63 & 35 & & 50 & 48 & \\
\hline
\end{tabular}

LNM = lymph node metastasis; $\mathrm{pT}=$ pathological tumor stage; $\mathrm{UBC}=$ urothelial bladder carcinoma Table 2 Expression of FOXM1 and $\beta$-catenin in $60 \mathrm{MIBC}$ and pair-matched paracarcinoma tissues. 


\begin{tabular}{|lllll|}
\hline & High expression & Low expression & $\mathbf{X}^{2}$ & P value \\
\hline F0XM1 & & & 4.625 & 0.031 \\
\hline carcinoma & 44 & 16 & & \\
\hline paracarcinoma & 24 & 36 & & \\
\hline B-catenin & & & 0.506 & 0.047 \\
\hline carcinoma & 45 & 15 & & \\
\hline paracarcinoma & 25 & 35 & & \\
\hline
\end{tabular}

Table 3 Univariate and multivariate analyses of FOXM1 and $\beta$-catenin expression in relation to OS in patients with MIBC 
Characteristic

Univariate

Hazard $\quad 95 \% \mathrm{Cl}$

Ratio
Multivariate

$\begin{array}{llll}P & \text { Hazard } & 95 \% \mathrm{Cl} & P \\ \text { value } & \text { Ratio } & & \text { value }\end{array}$

Age, years

$\geq 60$ vs $<60$

1.189

$0.705-$

2.003

$0.516 \quad 1.362$

$0.796-$

2.330

0.260

\section{Gender}

Male vs Female

0.879

$0.516-$

1.499

0.637

0.715

$0.413-$

1.239

0.232

pT classification

pT4 vs pT2-3

2.325

$1.352-$
3.998

$0.002 \quad 2.095$

$1.205-$

3.643

0.009

\section{Tumor grade}

3 vs $1-2$

2.790

$1.641-$

4.743

$<0.001 \quad 1.962$

1.120

3.439

0.019

Tumor size, $\mathbf{n}(\%)$

$\geq 3 \mathrm{~cm} v s<3 \mathrm{~cm}$

2.080

$1.123-$

3.854

$0.020 \quad 1.549$

0.819

2.930

0.178

\section{LNM}

Yes vs No

3.392

$1.937-$

5.937

$<0.001$

2.136

$1.160-$

3.935

0.015

\section{Recurrence status}

Yes vs No

2.016

$1.172-$

3.467

$0.011 \quad 0.574$

0.297

1.110

\section{Histological}

subtype

UBC vs Non-UBC

1.206

0.610

$0.590 \quad 1.355$

0.659

2.785

0.409

\section{FOXM1 expression}

High vs Low

2.986

$1.610-$

0.011

2.196

$1.150-$

4.194

0.017

\section{$\beta$-Catenin}

expression

High vs Low

2.623

$1.495-$
4.601

0.001

0.775

0.339

1.770

0.545 
$\mathrm{LNM}=$ lymph node metastasis; $\mathrm{pT}=$ pathological tumor stage; $\mathrm{UBC}=$ urothelial bladder carcinoma

\section{Figures}
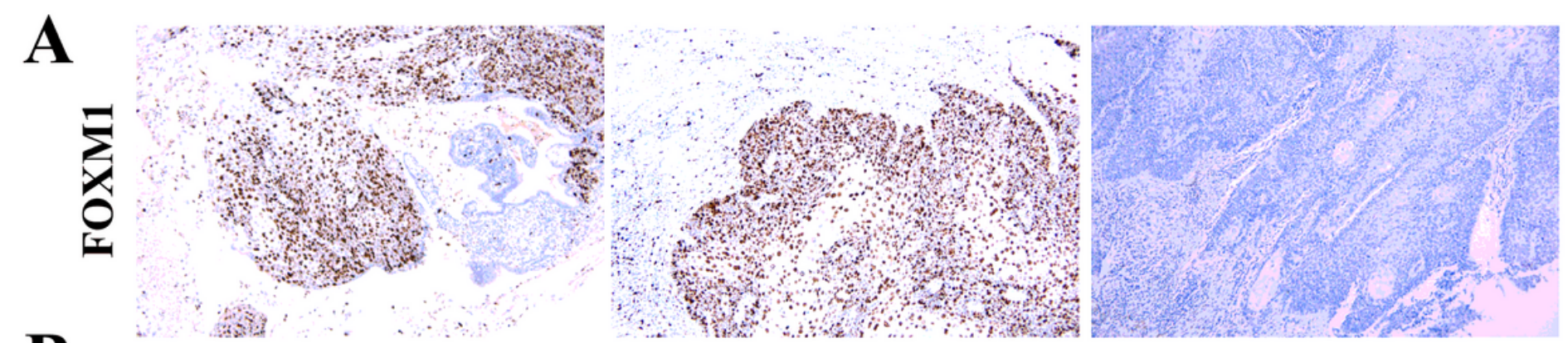

B

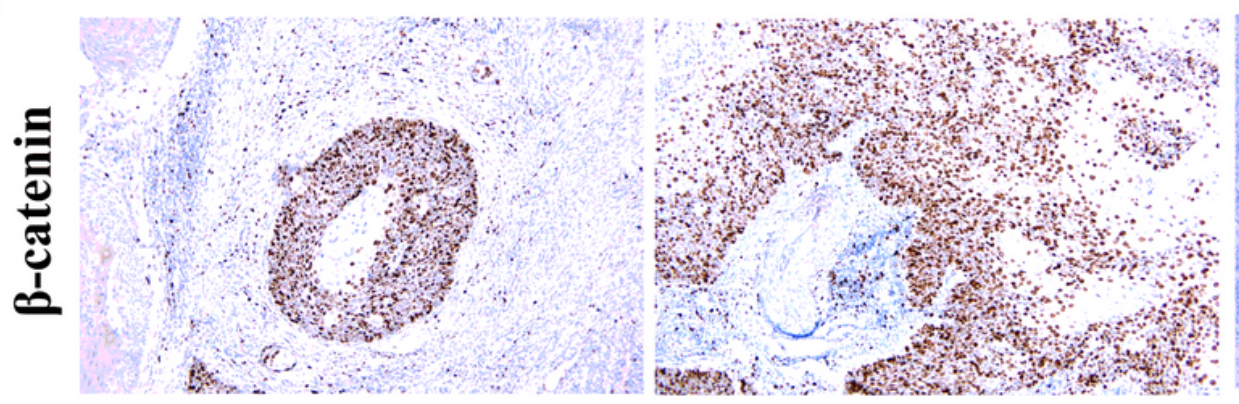

Normal

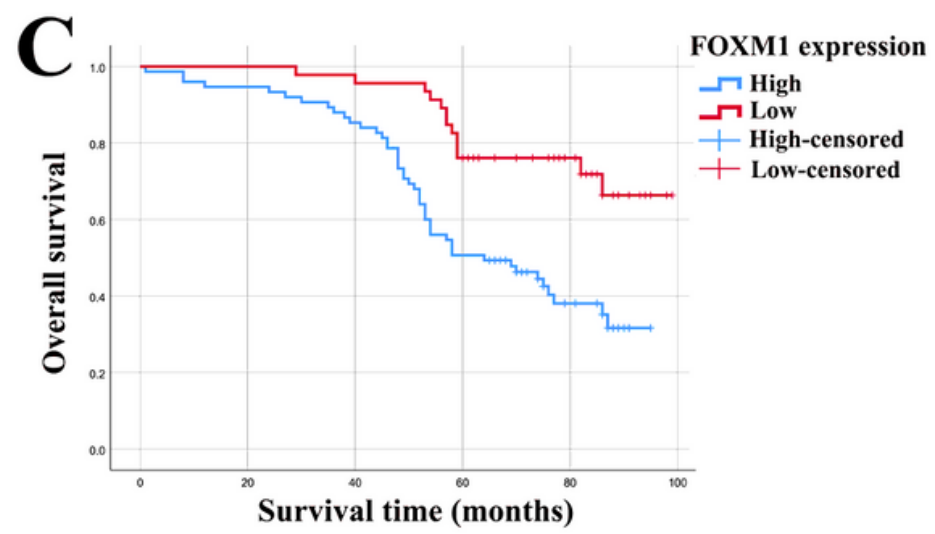

CA\#1

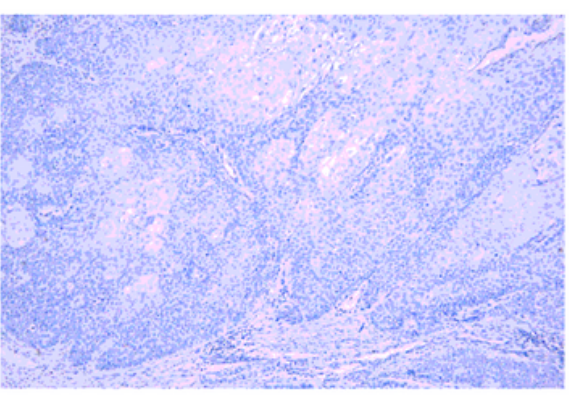

CA\#2

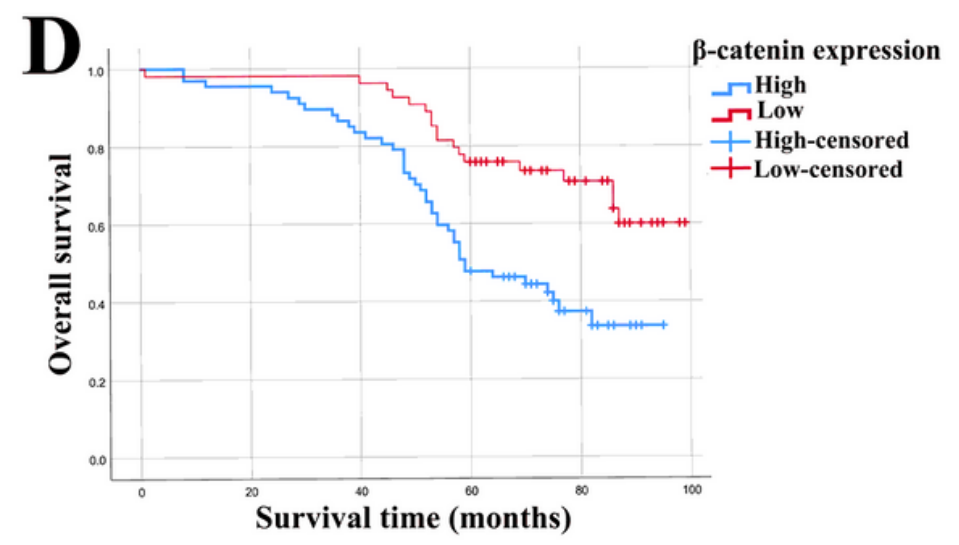

\section{Figure 1}

The expression of FOXM1 protein was assessed in the nuclei of primary bladder cancer cells, and the expression of $\beta$-catenin protein in tumor cells had different degrees of cytoplasmic and membrane staining characteristics, as shown in Figure $1 \mathrm{~A}$ and $\mathrm{B}$.We found that upregulate of FOXM1 and $\beta$-catenin expression (Fig 1C and D) were relevant to poor OS in MIBC patients by the Kaplan-Meier analyses $(\mathrm{P}<$ $0.05)$. 

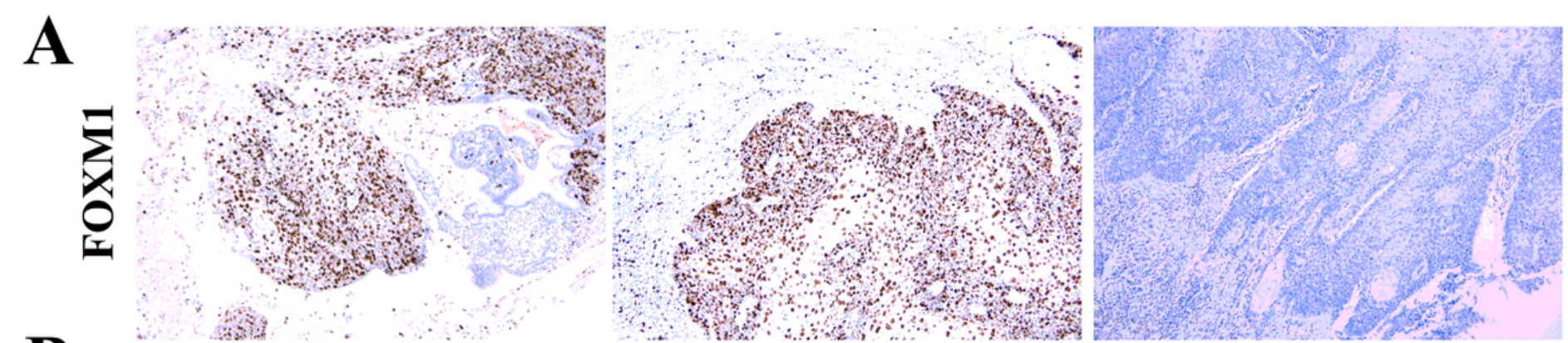

B

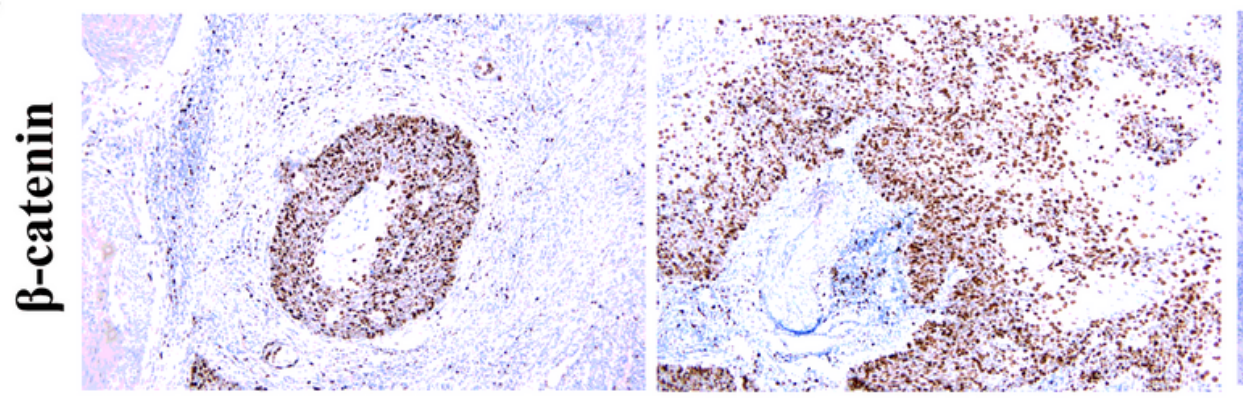

Normal

\section{CA\#1}

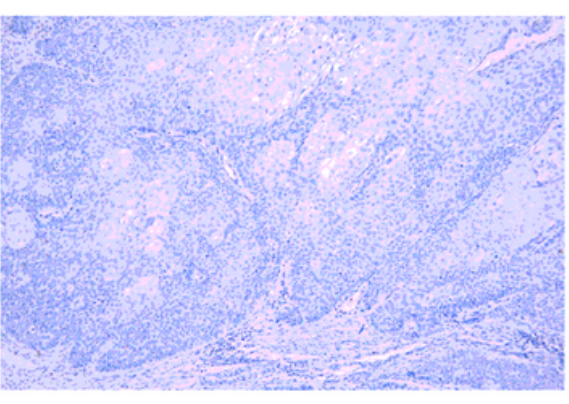

CA\#2
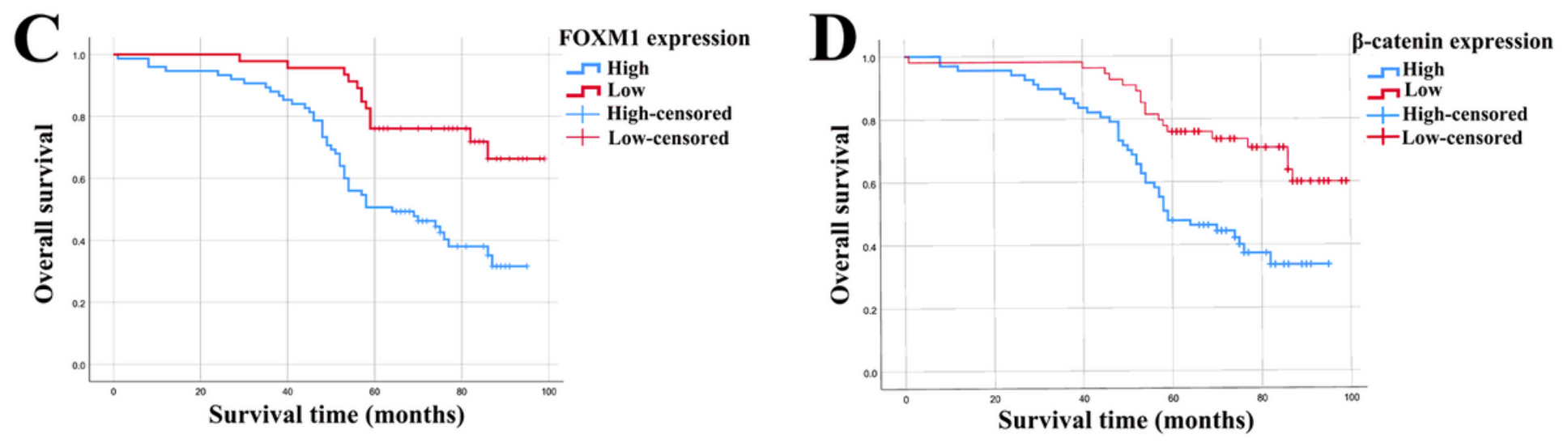

\section{Figure 1}

The expression of FOXM1 protein was assessed in the nuclei of primary bladder cancer cells, and the expression of $\beta$-catenin protein in tumor cells had different degrees of cytoplasmic and membrane staining characteristics, as shown in Figure $1 \mathrm{~A}$ and $\mathrm{B}$.We found that upregulate of FOXM1 and $\beta$-catenin expression (Fig 1C and D) were relevant to poor OS in MIBC patients by the Kaplan-Meier analyses $(\mathrm{P}<$ 0.05). 